\title{
WORKSHOP SIMULASI JARINGAN DASAR KOMPUTER MENGGUNAKAN CISCO PACKET TRACER
}

\author{
Hambali $^{1}$, Romy Aulia ${ }^{2}$, Mardalius ${ }^{3}$ \\ ${ }^{1,2,3}$ Program Studi Sistem Informasi, STMIK Royal Kisaran \\ email :'hambali@royal.ac.id,romysinggalang@gmail.com², mardalius18@gmail.com³
}

\begin{abstract}
Knowledge of computer science today is very necessary especially for students. One of them learns computer network which is a science that many people need. Associated with the existence of computer network so many jobs like send data, print paper to one printer by many computers easy to do. However, the knowledge of this is difficult to be able to by students in schools due to many obstacles such as incomplete equipment, competent tutors in their field no, that is experienced by students of SMA Negeri 1 Air Joman Kabupaten Asahan. Then need a solution that provides that knowledge. Cisco packet tracer which is a free application that can provide an overview of the computer network. With these applications it will be easy to provide knowledge of computer networks that can be provided through lectures, frequently asked questions and practice. The lecture method used is intended to provide a theoretical explanation of computer network material. Practice method is used to show directly how to make network cable and data communications. So that the benefits gained from this workshop activities is to increase students' knowledge of network technology and students are able to make a network connection with cable.
\end{abstract}

Keywords :Network, Computer, Cisco

\begin{abstract}
Abstrak :Pengetahuan akan ilmu komputer saat ini sangat diperlukan terkhusus untuk kalangan pelajar.Salah satunya belajar jaringan komputer yang merupakan ilmu yang banyak dibutuhkan masyarakat.Berhubungan dengan adanya jaringan komputer maka banyak pekerjaan seperti kirim data, cetak kertas ke satu printer oleh banyak computer mudah dilakukan. Namun, pengetahuan akan hal ini sulit di dapat oleh pelajar di sekolah berhubung banyak kendala seperti peralatan yang tidak lengkap, tutor yang berkompeten dibidangnya tida ada, itulah yang dialami oleh siswa SMA Negeri 1 Air Joman Kabupaten Asahan. Maka perlu solusi yang memberikan pengetahuan tersebut.Cisco packet tracer yang merupakan aplikasi gratis yang dapat memberikan gambaran atas jaringan komputer. Dengan aplikasi tersebut maka akan mudah memberikan pengetahuan akan jaringan komputer yang dapat diberikan melalui ceramah, tanya jawab dan praktek. Metode ceramah yang digunakan dimaksudkan untuk memberikan penjelasan secara teori terhadap materi jaringan komputer.Metode praktek digunakan untuk menunjukan langsung cara membuat kabel jaringan dan komunikasi data. Sehinga manfaat yang diperoleh dari kegiatan workshop ini adalah meningkatkan pengetahuan siswa terhadap teknologi jaringan dan siswa mampu membuat koneksi jaringan dengan kabel.
\end{abstract}

Kata kunci : Jaringan, Komputer, Cisco

\section{PENDAHULUAN}

Media dalam bahan ajar memiliki fungsi sebagai alat bantu untuk memperjelas pesan yang disampaikan guru.
Media juga berfungsi untuk pembelajaran individual dimana kedudukan media sepenuhnya melayani kebutuhan belajar siswa (pola bermedia). Azhar (2011) media pembelajaran adalah alat bantu pada proses 
Vol. 1, No. 2, Jul 2018, hlm. $33-40$

ISSN 2614-7912 (cetak)

ISSN 2622-3813 (online)

Available online at http://jurnal.stmikroyal.ac.id/index.php/jurdimas

belajar baik di dalam maupun diluar kelas, lebih lanjut dijelaskan bahwa media pembelajaran adalah komponen sumber belajar atau wahana fisik yang mengandung materi intruksional di lingkungan siswa yang dapat merangsang siswa untuk belajar. Proses pembelajaran merupakan proses komunikasi dan berlangsung dalam suatu sistem, maka media pembelajaran menempati posisi yang cukup penting sebagai salah satu komponen sistem pembelajaran. Tanpa media, komunikasi tidak akan terjadi dan proses pembelajaran sebagai proses komunikasi juga tidak akan bisa berlangsung secara optimal.

Begitu juga untuk belajar jaringan komputer dasar memerlukan media agar mudah dipahami secara mendasar sehingga pada prakteknya akan mudah pula dilaksanakan. Pemahaman akan pentingnya belajar jaringan komputer ini terus mengalami perkembangan begitu pesat dikarenakan pekerjaan yang dilakukan manusia membutuhkan distribusi data secara cepat dan terpusat. Oleh karena itu, penguasaan teknologijaringan komputer itu sendiri sangatlahdiperlukan, terutama bagi orang yangberkecimpung dan yang inginberkecimpung dalam bidang jaringan komputer. Pemahaman yang mendalam dalam hal jaringan komputer akan sangat membantu seorang administrator dalam mengelola jaringan komputer.

Jaringan komputer adalah perpindahandata (Komunikasi Data) dari suatu computer sumber (transmiter) ke komputer tujuan(receiver) yang melewati suatu media pengantar dalam bentuk bitbit. Salah satu contoh dari jaringan komputer adalah video conference pada komputer, dimana suara video yg dihantar harus diolah dalam bentuk bit-bit sebelum memasuki media penghantar untuk di komunikasikan (Stalling, 2015).

Dalam memberikan pemahaman yang komprehensif mengenai jaringan komputer tersebutdisini menggunakan aplikasi simulasi jaringan computer cisco packet tracer.Cisco Packet Tracer adalah simulator alat-alat jaringan cisco yang sering digunakan sebagaimedia pembelajaran dan pelatihan, dan juga dalam bidang penelitian simulasi jaringan komputer (Jesin A, 2014). Program ini dibuat oleh Cisco Systems dan disediakan gratis untuk fakultas, siswa dan alumni yang telah berpartisipasi di Cisco Networking Academy. Tujuan utama cisco paket tracer adalah untuk menyediakan alat bagi siswa dan pengajar agardapat memahami prinsip jaringan komputer dan juga membangun skill di bidang alat-alat jaringan Cisco.

Dengan cisco packet tracer ini memberikan kelancaran proses kegiatan pengabdian pada masyarakat yang dilaksanakan di SMA Negeri 1 Air Joman Kabupaten Asahan dimana memiliki satu ruangan laboratorium komputer dengan 10 unit personal komputer yang belum terhubung dengan jaringan LAN (Local Area Network) sehingga pada pelatihan ini diberikan penguatan pemahaman melalui simulasi cisco packet tracer agar ketika di dalam laboratorium sudah tidak buta lagi ketika merakit instalasi jaringan komputer.

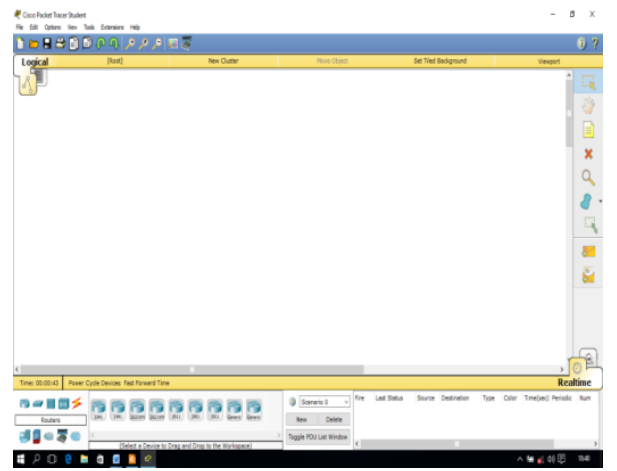

Gambar 1.Interface Cisco Packet Tracer

Hasil akhir yang diharapkan pada workshop simulasi jaringan dasar komputer menggunakan cisco packet tracer yang terhimpun dalam kegiatan pengabdian pada masyarkat di SMA Negeri 1 Air Joman Kabupaten Asahan adalah siswa akan menerapkan hasil pelatihan ini pada laboratorium komputer sehingga guru tutor tidak kerepotan lagi dalam memandu siswa-siswinya. 
Vol. 1, No. 2, Jul 2018, hlm. $33-40$

Available online at http://jurnal.stmikroyal.ac.id/index.php/jurdimas

\section{METODE}

Pengabdian Pada Masyarakat yang dilakukanpada SMA Negeri 1 Air Joman Kabupaten Asahan dilaksanakan karena adanya MOU kedua belah pihak sebelumnya. Pelaksanaannya pada hari sabtu tanggal 11 Nopember 2017 selama 8 jam dalam sehari yang diikuti oleh 30 orang siswa-siswi. Pengabdian Pada Masyarakat ini dilaksanakan dengan teknik:Simulasi, yaitu melakukan pengambaran terhadap materi yang akan dipelajari, Pelatihan, yaitu melakukan pengenalan terhadap perangkat-perangkat yang digunakan dan menunjukan cara instalasi dan kinerja perangkat tersebut, Pendampingan, yaitu melakukan konsultasi langsung selama proses pelatihan.

Sebelum pelaksanan workshop simulasi kami memberikan pretest untuk mengetahui sejauh mana siswa-siswi tersebut mengenal komputer dan menggunakannya. Hasil yang diperoleh menunjukan angka $60 \%$ berarti secara keseluruhan sudah mengenal komputer sehingga memudahkan kami untuk memberikan pelatihan tersebut.

Perangkat yang kami gunakan: (1) lcd; (2) personal computer; (3) notebook; (4) switch; (5) tank crimper; (6) kabel utp; (7) connector rj45; (8) cable tester

\section{PEMBAHASAN}

Pada pelaksanaan Pengabdian Masyarakat ini diberikan terlebih dahulu brainstorming mengenai jaringan komputer dasar.

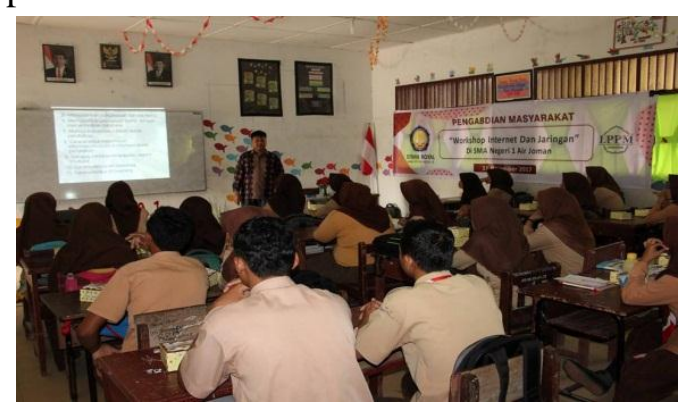

Gambar 2. Brainstorming
Ada beberapa jenis jaringan komputer bila dilihat dari cara pemprosesan data dan pengaksesannya :

1. Host-terminal

Dimana terdapat satu atau lebih serveryang dihubungkan dalam suatu dumb terminal. Karena dumb terminal hanyalah sebuah monitor yang dihubungkan dengan menggunakan kabel RS-232 maka pemrosesan data dilakukan didalam server. Oleh karenaitu, server tersebut haruslah sebuahsistem komputer yang memilikikemampuan pemrosesan data yangtinggi dan pemyimpanan data yangsangat besar

\section{Client-Server}

Dimana sebuah server atau lebih yang dihubungkan dengan beberapa client. Server bertugas menyediakan berbagai macam layanan, misalnya pengaksesan berkas, basis data. Sedangkan clientadalah sebuah terminal yang menggunakan layanan tersebut. Perbedaannya dengan hubungan dumb terminal adalah sebuah terminal client melakukan pemrosesan data diterminalnya sendiri dan hal itu menyebabkan spesifikasi dari server tidaklah harus memiliki performansi tinggi dan kapasitas penyimpanan datayang besar karena semua pemrosesan data yang merupakan permintaan dariclient dilakukan diterminal client

\section{Peer to Peer}

Dimana terdapat beberapa terminal komputer yang dihubungkan denga media jaringan komputer. Secara prinsip, hubungan peer to peer ini adalah bahwa setiap computer dapat berfungsi sebagai server dan client, keduanya dapat difungsikan dalam waktu yang bersamaan.

Sedangkan bila dilihat dari sisi jangkauannya, jaringan dapat dibagi menjadi 4 jenis :

1. Local Area Network (LAN)Adalah sebuahjaringan komputer yangbersifat lokal fisik jaringan komputernya, misalnya di satu ruang laboratorium komputer

2. Wide Area Network (WAN)Adalah sebuah jaringan computer antara satu 
Vol. 1, No. 2, Jul 2018, hlm. $33-40$

ISSN 2614-7912 (cetak)

ISSN 2622-3813 (online)

Available online at http://jurnal.stmikroyal.ac.id/index.php/jurdimas

gedung dengan gedung lainyang terletak agak berjauhan

3. Metropolitan Area Network (MAN)Adalah jaringan komputer yang melibatkan beberapa jaringan computer yang terhubung saru sama lain dansecara geografis tersebar cukup jauh,namun masih dalam satu wilayah ataukota.

Langkah membuat kabel Straight dan Cross

Kabel Straight

Kabel straight merupakan kabel yang memiliki cara pemasangan yang sama antara ujung satu dengan ujung yang lainnya.Kabel straight digunakan untuk menghubungkan 2 device yang berbeda. Urutan standar kabel straightadalah seperti dibawah ini yaitu sesuai dengan standar TIA/EIA 368B (yang paling banyak dipakai) atau kadang-kadang juga dipakai sesuai standar TIA/EIA 368A sebagai berikut:

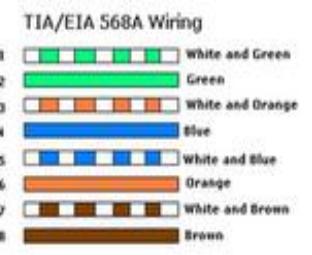

$$
\text { TIA/EIA } 568 B \text { Wiring }
$$

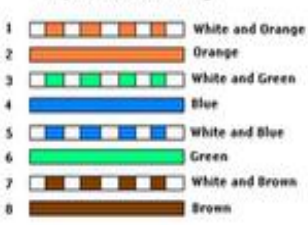

Gambar 3. Kabel Straight

Contoh penggunaan kabel straight adalah sebagai berikut :

- Menghubungkan antara computer dengan switch

- Menghubungkan computer dengan LAN pada modem cable/DSL

- Menghubungkan router dengan LAN pada modem cable/DSL

- Menghubungkan switch ke router

- Menghubungkan hub ke router

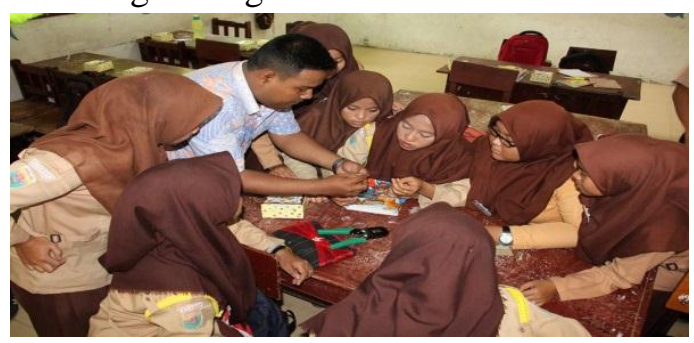

Gambar 4. Proses Pembuatan Kabel Straight

\section{Kabel Cross Over}

Kabel cross over merupakan kabel yang memiliki susunan berbeda antara ujung satu denganujung dua. Kabel cross over digunakan untuk menghubungkan 2 device yang sama. Gambar dibawah adalahsusunan standar kabel cross over.
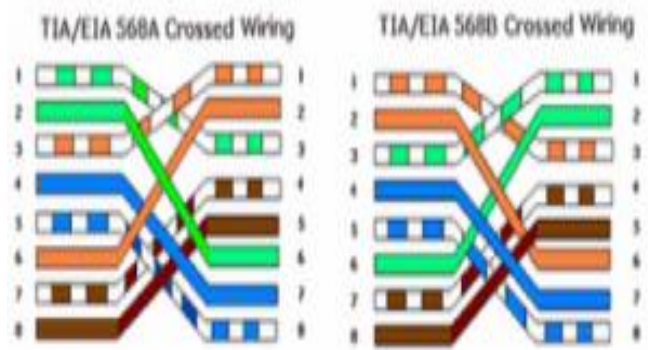

Gambar 5. Kabel Cross

Contoh penggunaan kabel cross over adalah sebagai berikut : Menghubungkan 2 buah komputer secara langsung, Menghubungkan 2 buah switch, Menghubungkan 2 buah hub Menghubungkan switch dengan hub, Menghubungkan komputer dengan router

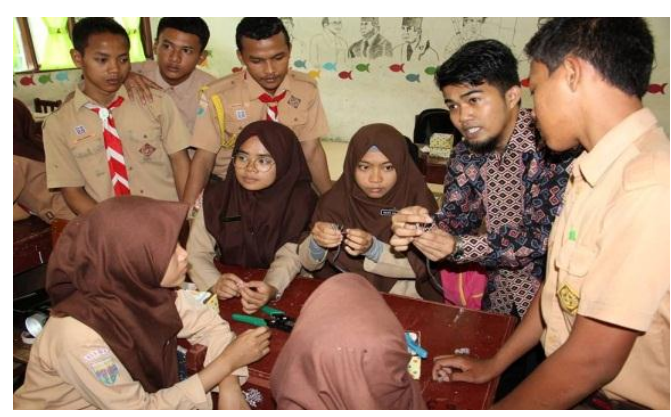

Gambar 6. Proses Pembuatan Kabel Cross Langkah-Langkah Cara Pemasangan Kabel UTP

Tipe Straight

Langkah 1 :

Kupas terlebih dahulu ujung kabel menggunakan alat pengupas kabel sekitar kurang lebih $2 \mathrm{~cm}$ sampai kabel yg terdapat di dalam nya terlihat :

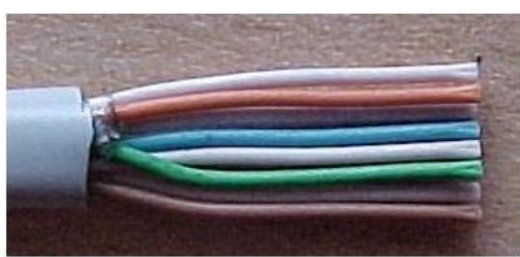

Gambar 7. Kupasan Kabel 
Vol. 1, No. 2, Jul 2018, hlm. $33-40$

Available online at http://jurnal.stmikroyal.ac.id/index.php/jurdimas

Langkah 2 :

Pisahkan kabel-kabel tersebut dan luruskan, susunlah kabel-kabel tersebut dengan rapih berdasarkan warna seperti Orange Putih, Orange, Hijau Putih, Biru, Biru Putih, Hijau, Coklat Putih, dan Coklat.

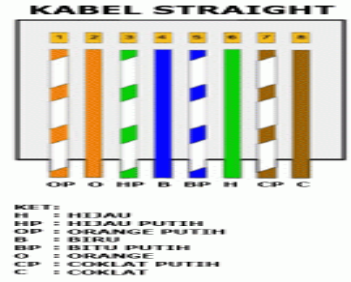

Gambar 8. Urutan Warna Kabel Straight Langkah 3 :

Setelah kabel tersusun, kemudian ambil Connector RJ-45, Connector ini terdiri dari 8 pin. Pin 1 dari connector ini adalah pin yang berada paling kiri.

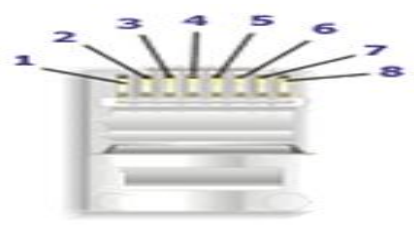

Gambar 9.Connector RJ45

Langkah 4 :

Masukkan kabel-kabel tersebut hingga bagian ujungnya mentok di dalam Connector dan sesuaikan dengan urutan :(1)Orange Putih pada Pin 1; (2)Orange pada Pin 2; (3)Hijau Putih pada Pin 3; (4)Biru pada Pin 4; (5)Biru Putih pada Pin 5; (6)Hijau pada Pin 6; (7)Coklat Putih pada Pin 7; (8)Coklat pada Pin 8

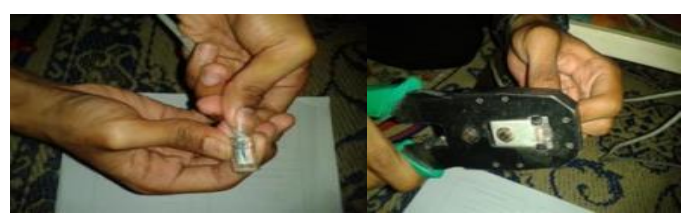

Gambar 10. Proses Pemasangan

Hasil dari susunan warna pada kabel straight setelah selesai pemasangan :

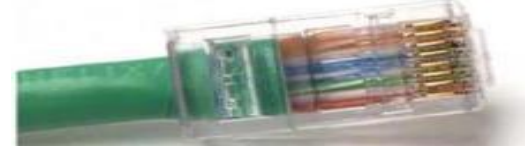

Gambar 11.Kabel Straight
Langkah 5 :

Setelah selesai menyusun kabel straight kemudian kita akan mencoba dengan menggunakan LAN tester masukkan ujung kabel ke alatnya, kemudian nyalakan, kalau lampu led yang pada LAN tester menyala semua, dari nomor 1 sampai 8 berarti Anda telah sukses.

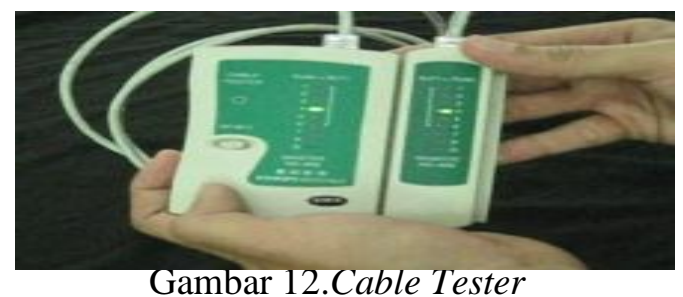

Langkah 6 :

Untuk cara pemasangan kabel yang kedua, langkah-langkahnya sama dengan pemasangan ujung kabel pertama. Ulangi langkah-langkah tadi untuk memasang connector RJ-45 pada ujung kabel yang kedua.

Tipe Cross

Langkah 1 :

Cara pemasangan kabel UTP tipe cross hampir sama dengan casa pemasangan kabel UTP tipe straight. Mengenai pemasanganya sama seperti pada pemasangan kabel straight. Hanya saja perbedaan terdapat pada urutan warna kabel pada ujung kabel yang keduanya. Untuk ujung kabel pertama susunan warna pada kabel cross: (1) Orange Putih pada Pin 1; (2)Orange pada Pin 2; (3)Hijau Putih pada Pin 3; (4)Biru pada Pin 4; (5)Biru Putih pada Pin 5; (6)Hijau pada Pin 6; (7)Coklat Putih pada Pin 7; (8)Coklat pada Pin 8.

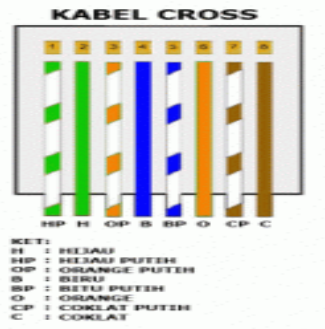

Gambar 13.Kabel Cross 
Vol. 1, No. 2, Jul 2018, hlm. $33-40$

Available online at http://jurnal.stmikroyal.ac.id/index.php/jurdimas

Setelah selesai menyusun kabel straight kemudian kita akan mencoba dengan menggunakan LAN tester masukkan ujung kabel ke alatnya, kemudian nyalakan. Susunan warna ujung kabel pertama berbeda dengan unjung kabel kedua. Nanti jika dites menggunakan LAN tester, maka nantinya led 1, 2, 3 dan 6 akan saling bertukar.

Simulasi Jaringan Komputer Cisco Packet Tracer Setelah mengenal perangkat dan tata cara perakitan kabel jaringan maka berikutnya dalam Pengabdian Pada Masyarakat ini menghubungkan dua komputer atau lebih melalui aplikasi simulator cisco packet tracer. Manfaat cisco packet tracer :

- Membuat mengajar lebih mudah dengantersedia gratis, multiuser dan instruktur lebih mudah mengajar untuk konsep lebih kompleks

- Membuat mengajar lebih mudah tersedia simulasi jaringan dan lingkungan visualirealistis

- Teresedia aktivitas belajar, penugasan, laboratorium dan ujian yang kompleks

- Mendukung perkuliahan, kelompok dan lab individual, pekerjaan rumah, tugas/ujian, studi kasus, game dan kompetisi

- Perlengkapan tambahan nyata dan membolehkan kesempatan belajar diperluas melebihi fisik di ruang kelas yang terbatas

- Mayoritas mendukung protocol dan teknologi kurikulum Akedemik Jaringan.

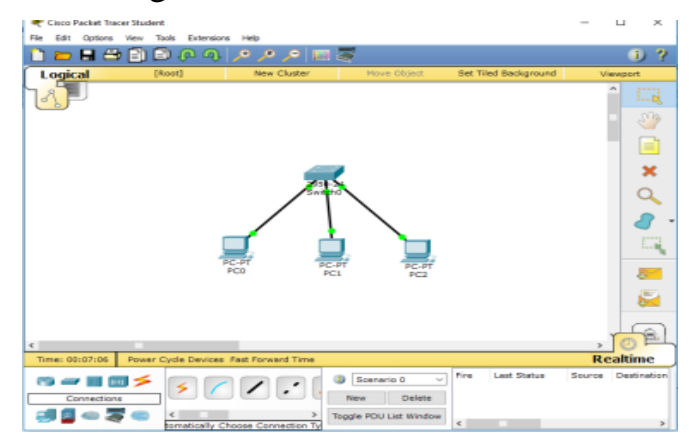

Gambar 14. Topologi Jaringan
Pada gambar 14 dapat dijelaskan bahwa 3 buah komputer saling berkomunikasi dikarenakan dihubungkan oleh switch dan kabel straight.Agar bisa saling bertukar data maka diatur IP Address :

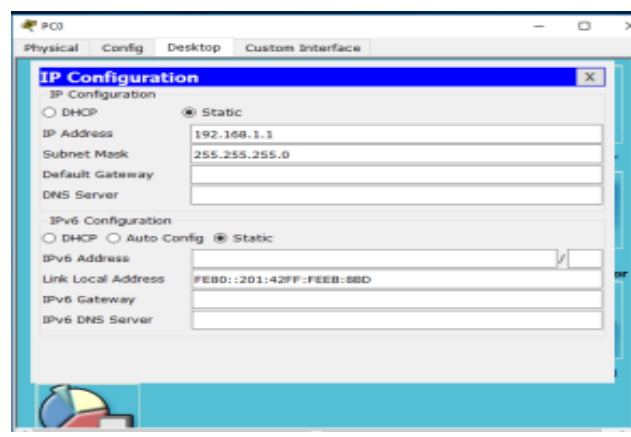

Gambar 15.Setting IP Address

IP Address untuk PC $0:$ : 192.168.1.1

IP Address untuk PC $1:$ : 192.168.1.2

IP Address untuk PC 2 : 192.168.1.3

Subnet mask masing-masing :

255.255.255.0, LAN ini menggunakan IP Address kelas C.

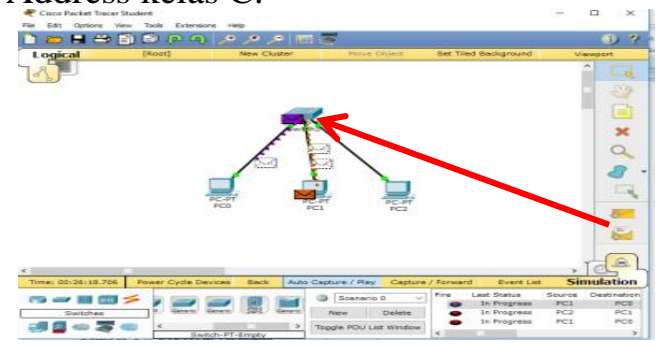

Gambar 16. Simulasi Komunikasi Data Bukti bahwa komunikasi berhasil dapat dilihat pada lingkaran merah gambar 17.Keberhasilan dalam komunikasi data perlu diperhatikan apakah kabel benar susunannya, switch baik, ip address dan subnetting benar dilakukan.

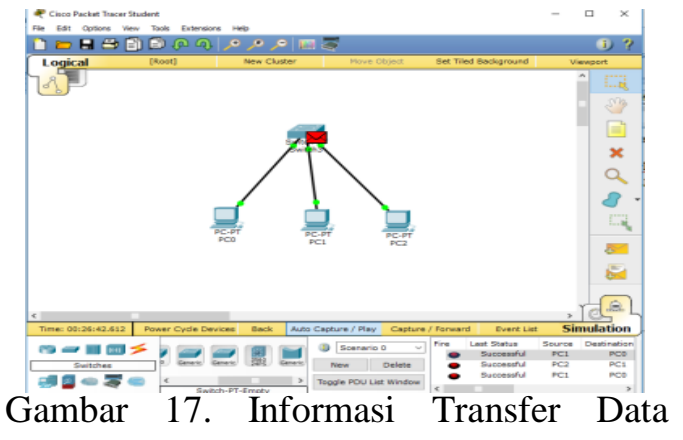


Tabel 1.Fitur Packet Tracer

\begin{tabular}{|c|c|c|}
\hline $\mathrm{NO}$ & MENU & PENJELASAN \\
\hline 1 & $\begin{array}{l}\text { Bagian } \\
\text { Menu }\end{array}$ & $\begin{array}{l}\text { Bagian ini menyediakan menu File, Edit, Option, View, Tool, } \\
\text { Extension dan Help. }\end{array}$ \\
\hline 2 & $\begin{array}{l}\text { Bagian } \\
\text { Tool } \\
\text { Utama }\end{array}$ & $\begin{array}{l}\text { Bagian ini menyediakan Shortcut Icon perintah Filedan Edit. Juga } \\
\text { perintah Copy, Paste, Undo, Redo, Zoom danPalette Drawing }\end{array}$ \\
\hline 3 & $\begin{array}{l}\text { Bagian } \\
\text { Tool } \\
\text { umum }\end{array}$ & 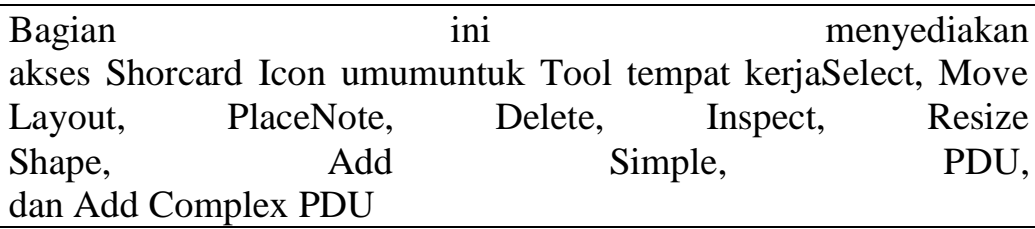 \\
\hline 4 & $\begin{array}{l}\text { Bagian } \\
\text { Navigasi } \\
\text { dan } \\
\text { Logical } \\
\text { /Physical }\end{array}$ & 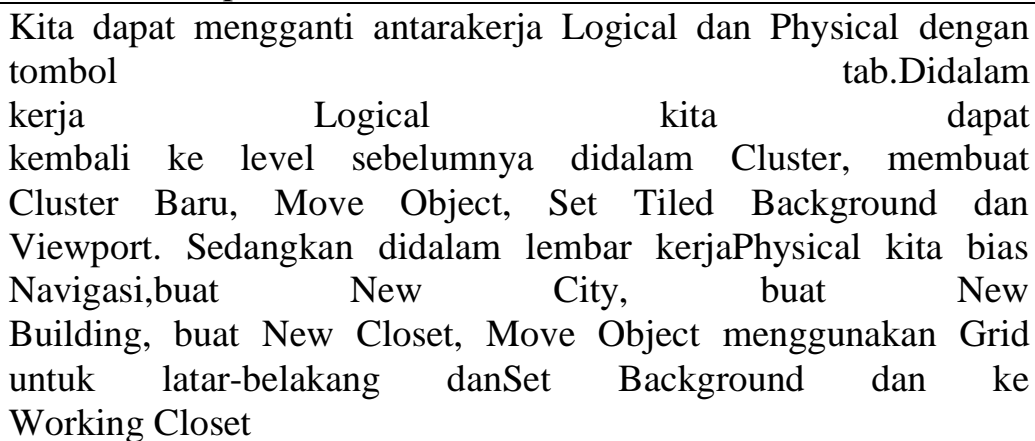 \\
\hline 5 & Works & 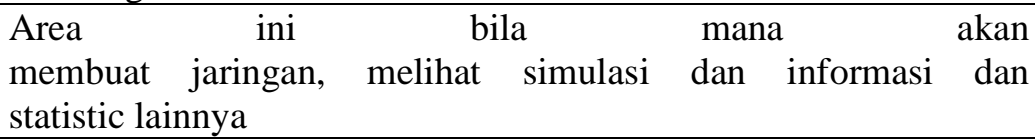 \\
\hline 6 & $\begin{array}{l}\text { Bagian } \\
\text { Realtime / } \\
\text { Simulation }\end{array}$ & $\begin{array}{l}\text { Digunakan untuk menggantiantara Realime Mode danSimulation } \\
\text { Mode dengan tabsdihidupkan. Juga penggunaanDevice Type } \\
\text { Selection danDevice-Specific SelectionBox }\end{array}$ \\
\hline 7 & $\begin{array}{l}\text { Bagian } \\
\text { komponen } \\
\text { Jaringan }\end{array}$ & $\begin{array}{lccc}\text { Bagian ini digunakan untuk memilih perangkat } & \text { dan } \\
\text { menghubungkan diletakkan didalam lembar kerja. } & \text { Yang } \\
\text { didilamnya } & \text { berisi } & & \text { kotak } \\
\text { Device-Type Selection dankotak Device-SpecificSelection } & \end{array}$ \\
\hline 8 & $\begin{array}{l}\text { Kotak } \\
\text { Device } \\
\text { Type } \\
\text { Selection }\end{array}$ & $\begin{array}{lcrr}\text { Bagian } \quad \text { ini } & \text { berisi } & \text { jenis } \\
\text { perangkat } & \text { dan } & & \text { koneksinya. } \\
\text { Dapat memilih tipe perangkatyang dibutuhkan } & \end{array}$ \\
\hline 9 & $\begin{array}{l}\text { Kotak } \\
\text { Device } \\
\text { Specific }\end{array}$ & $\begin{array}{l}\text { Bagian } \\
\text { yang } \\
\text { yang ada }\end{array}$ \\
\hline 10 & $\begin{array}{l}\text { Jendala } \\
\text { Pengguna } \\
\text { membuat } \\
\text { Paket }\end{array}$ & $\begin{array}{l}\text { Jendela ini untuk mengatur paket-paket yang diletakkandalam } \\
\text { scenario simulasijaringan. Lihat seksi lebihdetailnya dalam } \\
\text { "Simulasition Mode" }\end{array}$ \\
\hline
\end{tabular}


Vol. 1, No. 2, Jul 2018, hlm. $33-40$

ISSN 2614-7912 (cetak)

ISSN 2622-3813 (online)

Available online at http://jurnal.stmikroyal.ac.id/index.php/jurdimas

Kegiatan pelatihan ini dapat berjalan dengan lancar.Hal ini disebabkan adanya factor yang mendukung berjalannya kegiatan pengabdian.Hal-hal yang mendukung berjalannya kegiatan pengabdian ini dapat diidentifikasi diantaranya antusiasme para peserta pelatihan.

Antusiasme para peserta dibuktikan dengan banyaknya pertanyaan yang muncul ketika pelaksanaan diskusi dan hands Onpelatihan.

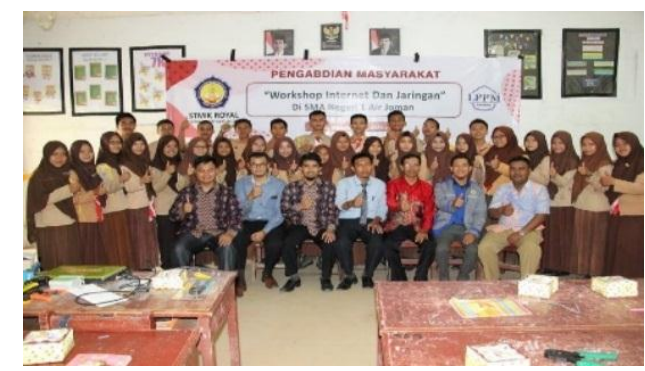

Gambar 18. Para Peserta dan Instruktur Pengabdian Masyarakat

\section{SIMPULAN}

Dari hasil kegiatan pengabdian masyarakat ini dapat diambil kesimpulan bahwa pengenalan perangkat jaringan dasar komputer dan perakitan berhasil dilaksanakan.Begitu juga terhadap simulasi hubungan koneksi dua komputer atau lebih mudah dipahami.

\section{UCAPAN TERIMA KASIH}

Pada kesempatan ini kami mengucapkan terima kasih kepada pendonor dana terlaksana dengan sukses
Pengabdian Pada Masyarakat ini ditujukan kepada Yayasan Royal Teladan Asahan. Selanjutnya kepada Kepala Sekolah SMA Negeri 1 Air Joman Kabupaten Asahan yang menyediakan tempat terlaksananya kegiatan ini.

\section{DAFTAR PUSTAKA}

Abas., AP. (2011). Perangkat Lunak Simulasi Packet Tracer Untuk Pendidikan.Jurnal DASI. 12 (2) : 16

Alimuddin., Y \& Roys., P. (2018). Penggunaan Software Simulator Untuk Pembelajaran Jaringan Komputer.Jurnal Pendidikan, Sosial dan Budaya IDEAS. 4 (2) : 225-229

Bambang., I. (2016). Pelatihan Dan Instalasi Jaringan Lan (Local Area Network)

Untuk Guru-Guru Di Yayasan Perguruan Birrul WaalidainSemplak Bogor. Jurnal Abdimas. 2 (2) : 1-5

Mufadhol.(2012). Simulasi Jaringan Komputer

Menggunakan Cisco Packet Tracer.Jurnal Transformatika. 1 (2) : 64-71

Paryanta.(2016). Media Pembelajaran Sistem Jaringan KomputerDan Internet Berbantuan Komputer Dengan Model Tutorial.Indonesian Journal on Networking and Security (IJNS). 5 (2) : 1-8

Yuri., YJ. (2013). Perancangan Program Simulasi

Perintah Dasar Jaringan Komputer.Jurnal Ilmiah Foristek. 3 (2) : 294-301 